\title{
Nonalcoholic fatty liver disease as trigger of cardiovascular and metabolic complication in metabolic syndrome
}

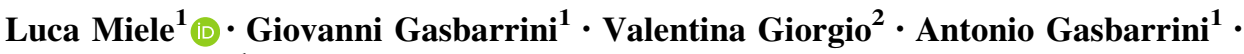 \\ Antonio Grieco ${ }^{1}$
}

Received: 6 February 2015/Accepted: 22 October 2015/Published online: 24 November 2015

(C) SIMI 2015

$\begin{array}{ll}\text { Abbreviations } \\ \text { NAFLD } & \text { Nonalcoholic fatty liver disease } \\ \text { MS } & \text { Metabolic syndrome } \\ \text { T2DM } & \text { Type } 2 \text { diabetes } \\ \text { NASH } & \text { Nonalcoholic steatohepatitis } \\ \text { CVD } & \text { Cardiovascular disease } \\ \text { SIBO } & \text { Small intestine bacteria overgrowth }\end{array}$

\section{Introduction}

Nonalcoholic fatty liver disease (NAFLD) is actually considered the main cause of chronic liver disease. The term NAFLD encompasses the entire spectrum of liver damage ranging from simple fat accumulation in the liver (steatosis), to nonalcoholic steatohepatitis (NASH), characterized by steatosis together with inflammation and ballooning, and possible onset of fibrosis to cirrhosis and liver cancer.

The high prevalence of NAFLD is becoming a social and health challenge. In Europe it is estimated to have a prevalence of $40 \%$ in general population, but a similar figure has also been reported in the US and Asia [1, 2].

It is reported that nearly $90 \%$ of NAFLD patients have one or more cardio-metabolic risk factors (hyperglycemia,

Luca Miele

luca.miele@rm.unicatt.it

1 Internal Medicine, Gastroenterology and Liver Unit, Fondazione Policlinico Gemelli, Catholic University of Sacred Heart, Largo Gemelli 8, 00168 Rome, Italy

2 Pediatric Department, Fondazione Policlinico Gemelli University Hospital, Catholic University of Sacred Heart, Rome, Italy dyslipidemia, hypertension and visceral adiposity), these factors are clustered in the definition of Metabolic Syndrome (MS) as exemplified in Table 1 [3]. For this reason, NAFLD is considered as the liver manifestation of MS [1]. Moreover, the incidence of diabetes is high in subjects with a fatty liver, and type 2 diabetes mellitus (T2DM) is able to influence the natural history of NAFLD by facilitating the progression of fibrosis to cirrhosis and the onset of liver cancer $[2,5]$. The prevalence of fatty liver increases to $80-90 \%$ in diabetics and obese subjects. Considering the increasing prevalence of an 'unhealthy' lifestyle (increased diffusion of 'hyper-caloric' diet associated with low physical activity), the incidence of NAFLD and MS is continuing to rise, even in apparently healthy subjects [3, 4].

While the natural history of simple steatosis is considered unremarkable, the presence of NASH and fibrosis is associated with the possible risk of developing cirrhosis or liver cancer and cardio-metabolic comorbidity (cardiovascular disease and onset of diabetes). Interestingly, cardiovascular complications are the leading cause of morbidity and mortality in NAFLD subjects [5-7]. Moreover, the presence of MS leads to an increased risk of T2DM and cardiovascular disease (CVD), leading these subjects to be a high-risk group for increased morbidity and allcause mortality with a shortened lifespan compared with the general population.

For these reasons, NAFLD subjects should now be considered as a 'risk population' for increased morbidity and mortality due to progressive liver disease or cardiovascular complications, independently from classical known risk factors. Moreover, fatty liver should be considered as a primary target for prevention of MS to reduce the possible burden of economic costs for health systems by 2020 [8]. 
Table 1 Metabolic Syndrome components: definitions by the International Diabetes Federation (IDF), the World Health Organization (WHO) and the Adult Treatment Panel III (ATPIII)

\begin{tabular}{|c|c|c|c|}
\hline Component & IDF & WHO & ATPIII \\
\hline $\begin{array}{l}\text { Elevated waist } \\
\text { circumference }\end{array}$ & $\begin{array}{l}\text { Population-specific definitions } \\
\text { For Euopids: } \\
>94 \mathrm{~cm} \text { (males) } \\
>80 \mathrm{~cm} \text { (females) }\end{array}$ & $\begin{array}{l}\text { Waist } / \text { hip ratio }>0.90 \text { (male) } \\
>0.85 \text { (female) } \\
\text { or } \mathrm{BMI}>30 \mathrm{~kg} / \mathrm{m}^{2}\end{array}$ & $\begin{array}{l}>102 \mathrm{~cm} \text { (males) } \\
>88 \mathrm{~cm} \text { (females) }\end{array}$ \\
\hline $\begin{array}{l}\text { Elevated triglycerid } \\
\text { Reduced HDL cholesterol }\end{array}$ & $\begin{array}{l}\geq 150 \mathrm{mg} / \mathrm{dl} \text {-or } 1.7 \mathrm{mmol} / \mathrm{L}^{\mathrm{a}} \\
<40 \mathrm{mg} / \mathrm{dl} \text {-or } 1.03 \mathrm{mmol} / \mathrm{L} \text { - }(\text { males }) \\
<50 \mathrm{mg} / \mathrm{dl} \text {-or } 1.29 \mathrm{mmol} / \mathrm{L} \text { - }\left(\text { females) }{ }^{\mathrm{a}}\right.\end{array}$ & $\begin{array}{l}\geq 1.695 \mathrm{mmol} / \mathrm{L} \\
\leq 0.9 \mathrm{mmol} / \mathrm{L} \text { (males) } \\
\leq 1.0 \mathrm{mmol} / \mathrm{L} \text { (females) }\end{array}$ & $\begin{array}{l}\geq 150 \mathrm{mg} / \mathrm{dl} \text {-or } 1.7 \mathrm{mmol} / \mathrm{L} \text { - } \\
<40 \mathrm{mg} / \mathrm{dl} \text {-or } 1.03 \mathrm{mmol} / \mathrm{L} \text { - (males) } \\
<50 \mathrm{mg} / \mathrm{dl} \text {-or } 1.29 \mathrm{mmol} / \mathrm{L} \text { - (females) }\end{array}$ \\
\hline Elevated blood pressure & $\begin{array}{l}\text { Systolic } \geq 130 \mathrm{mmHg} \\
\text { Diastolic } \geq 85 \mathrm{mmHg}^{\mathrm{a}}\end{array}$ & $\begin{array}{l}\text { Systolic } \geq 140 \mathrm{mmHg} \\
\text { Diastolic } \geq 90 \mathrm{mmHg}\end{array}$ & $\geq 130 / \geq 85 \mathrm{mmHg}$ \\
\hline Other & Elevated fasting glucose $\geq 100 \mathrm{mg} / \mathrm{dl}^{\mathrm{a}}$ & $\begin{array}{l}\text { Urinary albumin excretion ratio } \\
\geq 20 \mu \mathrm{g} / \mathrm{min} \\
\text { or albumin/creatinine ratio } \\
\geq 30 \mathrm{mg} / \mathrm{g}\end{array}$ & $\geq 110 \mathrm{mg} / \mathrm{dL}$ \\
\hline
\end{tabular}

${ }^{a}$ Drug treatment for this condition is an alternate indicator

Elucidating the mechanism of progression of liver disease and the link with cardiometabolic risk is mandatory for improving therapeutic targets.

\section{NALFD: the liver at the center}

For several years fatty liver was considered as a 'silent bystander', but now the matter of debate is if fatty liver disease is a cause or a consequence of the clinical features of MS [9-13].

The common connection between MS and NAFLD is abnormal lipid traffic and its consequences, such as visceral adiposity and insulin resistance [14]. The pathophysiology is very complex, and not yet clear [15]. The majority of patients are obese, elderly, sedentary, and have insulin resistance. However, despite the importance of obesity, sometimes even patients who have a normal weight may be insulin resistant, and be diagnosed with the syndrome. There are clinical conditions in which NAFLD seems to be independent from insulin resistance, i.e., HCV (genotype 3a) infection, drugs, and familial hypobetalipoproteinaemia [16, 20, 21]. Recently a large genome-wide association study (GWAS) describes a single-nucleotide polymorphism (SNP) rs738409 in the gene encoding patatin-like phospholipase domain-containing protein 3 (PNPLA3) as a major determinant of the natural history of NAFLD, [even in the absence of insulin resistance [17, 23].

Besides PNPLA3, additional SNPs of genes implicated in NASH pathogenesis have been shown to influence liver damage and fibrosis progression in pediatric case-control studies. SNPs have been found in genes encoding for: the manganese superoxide dismutase (SOD2) regulating mitochondrial import and anti-oxidant activity [18]; the transcription factor Kruppel-like factor 6 (KLF6) regulating metabolism in hepatocytes and fibro genesis in hepatic stellate cells [19]; and the lipin-1 regulating the flux of free fatty acids between the adipose tissue and the liver whose expression is deregulated during steatosis [22]. Finally, there is a growing awareness that phenotypic expression of some genetic variants may be age-related. For example, a common variant (rs13412852) influencing the expression of lipin-1 is associated with lipid levels, NASH severity and hepatic fibrosis in children with NAFLD, whereas it influences body mass in adults of the same ethnicity [23].

However, the reason why only a minority of fatty livers progress to more severe disease and develop cardiovascular and metabolic complication remains under debate. Looking at the pathophysiology, the models that explain the progression of liver damage can help to an understanding of the clinical scenario. For several years the elegant 'two-hit' model was widely accepted to explain the natural history of fatty liver disease [20], The 'two-hit' hypothesis suggests a sequential model for explaining the liver damage supporting the axiom that fat deposition in the liver precedes inflammation. This model has recently been replaced by the "multiple hits hypothesis," a parallel model in which inflammation may anticipate steatosis [28]. Within a parallel model, the gut, adipose tissue and innate immunity are the sources of multiple stimuli that exert influence on the adipokine and cytokine network.

Different mechanisms lead to the deposition of fat within the liver. Approaching the fat deposition from a biochemical point of view, the excess of FFAs within the liver increase insulin resistance, facilitating the onset of the stigmata of MS [29]. Hyperinsulinaemia, caused by insulin 
resistance, results in an increased hepatic de novo lipogenesis and impaired inhibition of adipose tissue lipolysis, that ultimately leads to an increased efflux of free fatty acids from the adipose tissue to the liver. The liver experiences an initial hepatic infiltration, and becomes extremely vulnerable to a series of hits that may follow, leading to hepatocyte injury and progression from simple steatosis to NASH and fibrosis. Such multiple pathogenesis factors may include oxidative damage, unregulated hepatocyte apoptosis, activation of the profibrogenic transforming growth factor (TGF)-beta pathway, deregulation of multiple adipokines and hepatic stellate cell activation [21].

An increased intestinal permeability in NAFLD patients may alter the gut-liver balance contributing to the activation of the inflammatory cascade in the liver, thus enhancing the progression of the disease to NASH $[22,23]$.

Two main components of MS, glucose and triglycerides, are overproduced by the fatty liver, which seems therefore a key determinant of metabolic abnormalities.

Recent data regarding the fatty infiltration of the liver underlines a determinant role in: (1) the progression of liver damage to cirrhosis and liver cancer; (2) proinflammatory status, thus leading to the cluster of the cardiovascular and metabolic risk, a fingerprint of MS.

Besides genetic factors, the so called 'gut-liver-axis,' plays a major role among the environmental factors once involved in disease progression. NAFLD is associated with increased intestinal permeability (IP), and overgrowth of small bowel bacteria (SIBO) $[22,24]$. In in vitro and animal models of NAFLD, increased IP, and alterations of gut microbiota have been shown to increase the exposure of the liver to gut-derived bacterial products [such as lipopolysaccharides (LPS)], which may cause low-grade endotoxemia in the portal system [24]. Both IP and the prevalence of SIBO appear to be correlated with the severity of steatosis [25]. Bacterial products belong to distinct classes of endogenous signals, triggering the host immune response by the activation of Toll-Like Receptors (TLRs) [26]. In NASH patients, even low blood levels of endotoxemia can activate TLRs pathways in the liver. TLRs are expressed in the liver in von-Kupffer cells, biliary epithelial cells, hepatocytes, hepatic stellate cells (HSC), epithelial cells and dendritic cells of the liver [24]. While immune cell recruitment exerts a containment action against pathogens, it can also result in host tissue damage through cytokines, such as TNF- $\alpha$, which mediate the inflammatory responses. A wide range of data demonstrate that LPS is elevated in experimental models of hepatic fibrosis and in patients with cirrhosis [25, 26]. There is evidence that alterations of the intestinal microbiota, and a failure of the intestinal mucosal barrier, cause increases in bacterial translocation and LPS levels, especially in the later stages of hepatic fibrosis and cirrhosis [27, 29].
Recent studies on mice models demonstrate the crucial role for the LPS-TLR4 pathway in hepatic fibrogenesis. Modulating intestinal microflora and consequent endotoxemia levels through the use of probiotics and selective intestinal decontamination may open new ways to avoid NAFLD complications with hepatic fibrosis, cirrhosis and HCC. Therefore, it is conceivable that probiotics administration to such patients can reset the "leaky gut" of NAFLD patients, offering an interesting approach to counteract liver damage in NAFLD [30].

Fatty liver is commonly associated with obesity and insulin resistance, which are two of the main features of MS [31]. Similarly to NAFLD, MS is triggered by a combination of genetics and environmental factors, such as excess caloric intake and sedentary lifestyle. A central role in the MS pathogenesis is played by insulin resistance [32]. Insulin resistance is principally due to accumulation of excessive fat in ectopic tissues, such as liver, interfering with the normal insulin signaling pathway. The consequence is the reduction in glucose transformation to glycogen, and increased lipid accumulation in triglycerides. Although not part of the diagnostic criteria for MS, NAFLD is considered one of the main pathophysiological conditions associated with it. A study recently conducted in China on a quite large population, aimed at further exploring the relationship between NAFLD and MS, and evaluates the value of NAFLD as a marker for predicting the risk of MS in a prospective cohort from a large urban population. In an adjusted model for confounding factors, such as age, metabolic factors, smoke and exercise, the Hazard Ratios [HRs (95\% CIs)] of NAFLD for predicting MS are 2.06 $(1.72,2.46)$ and $1.55(1.39,1.72)$ in female and male populations, respectively. The authors conclude that NAFLD is an independent risk factor for predicting the risk of MS, and the patients with NAFLD should initiate weight and dietary control to prevent the occurrence of MS [33]. This finding corroborates the central role of insulin resistance in the pathogenesis of MS, enhanced by the coexistence of fatty liver [34]. The presence of obesity among the main clinical features of both NAFLD and MS closely parallels these conditions [35]. There are abundant data showing a relationship between obesity and NAFLD [35-38]. An Italian study evaluated the risk factors associated with hepatic steatosis. A total of 257 participants were enrolled. Compared with controls, steatosis is more common by 2.8 -fold in heavy drinkers, 4.6 -fold in obese persons and 5.8-fold in obese heavy drinkers. In heavy drinkers, obesity increases the risk of steatosis twofold, while heavy drinking is associated with only a onefold increased risk in obese subjects [39]. The authors conclude that steatosis is more strongly associated with obesity than with heavy drinking.

However, evidence of an etiologic association between NAFLD and MS has also been shown in non-obese patients 
[40]. Patients with NASH, even when non-obese, are more insulin resistant than patients with fatty liver alone [41]. It is hypothesized that liver damage itself leads to chronic hyperinsulinemia and insulin resistance from impaired insulin degradation, as it is seen in cirrhosis.

Several large population studies have highlighted the clinical implications of additional factors in MS pathogenesis, such as the immune system, dysregulation of the hypothalamic-pituitary-adrenal axis, increases in cellular oxidative stress, and renin-angiotensin-aldosterone system activity [42]. A proinflammatory and prothrombotic state has been widely described in MS, and derives largely from the secretory activity of adipose tissue, particularly intraabdominal or visceral fat. Contrary to the former concept of fat as an inert tissue mass, adipocytes are increasingly being recognized as secretory entities. Cytokines and other inflammatory markers or signaling molecules released by adipocytes contribute to onset of insulin resistance and thrombotic state [43].

This continuous, low-grade pro-inflammatory and thrombotic environment is shared by both NAFLD and MS. In both conditions visceral adipose tissue participates in producing most adipokines, which are involved in inducing insulin resistance and low-grade inflammation. Leptin is a satiety adipokine, produced predominantly in adipocytes, which regulates appetite and metabolism at the level of the hypothalamus [44]. Most obese humans have high circulating levels of leptin, as a result of what has been characterized as leptin resistance. This phenomenon of leptin resistance may already be present in obese children. Adiponectin is an adipose-specific hormone that has anti-inflammatory and insulin-sensitizing properties [45]. Observational studies have shown an inverse correlation between plasma adiponectin concentrations and adiposity, insulin resistance and hepatic fat [43-45]. Resistin is another adipokine that antagonizes insulin action, causing glucose intolerance, resistin-deficient animals are protected from obesity, whereas an elevated resistin level is associated with insulin resistance [46]. Both TNF-alpha and IL-6 are positively related to adiposity, and correlate with insulin resistance and CVD risk factors [47].

The pro-inflammatory cytokines tumor necrosis factor- $\alpha$ (TNF- $\alpha$ ) and interleukin-6 (IL-6) are critically involved in the pathophysiology of NAFLD. More advanced fibrosis is accompanied by increased TNF- $\alpha$ expression, and IL- 6 is among the first cytokines to be implicated as a predictor and pathogenetic marker of insulin resistance [48, 49]. The progression from simple steatosis through NASH remains controversial. While some authors believe them to be independent conditions, more recent data suggest a direct progression from steatosis to NASH as predicted by the two-hit theory. [50].
Table 2 Role of coffee and tobacco consumption in NAFLD and MS

\begin{tabular}{|c|c|c|}
\hline & NAFLD & MS \\
\hline $\begin{array}{l}\text { Coffee } \\
\text { consumption }\end{array}$ & $\begin{array}{l}\text { Protective role: } \\
\text { Antioxidant } \\
\text { Hepatoprotective (reduces } \\
\text { pro-inflammatory } \\
\text { cytokines) } \\
\text { Gut microbiota modulator }\end{array}$ & $\begin{array}{l}\text { Protective role: } \\
\text { Lypolitic effect } \\
\text { Improves glucose } \\
\text { tolerance }\end{array}$ \\
\hline $\begin{array}{l}\text { Smoking of } \\
\text { tobacco }\end{array}$ & $\begin{array}{l}\text { Secondhand tobacco } \\
\text { exposure associated with } \\
\text { NAFLD in children } \\
\text { Increase risk of HCC if } \\
\text { associated to T2DM }\end{array}$ & $\begin{array}{l}\text { Non protective: } \\
\text { Associated with } \\
\text { increased waist } \\
\text { circumference } \\
\text { Increases CVD risk } \\
\text { Increases insulin } \\
\text { resistance }\end{array}$ \\
\hline
\end{tabular}

Since food pattern and behaviour may influence microbiota, several nutrients have been indicated as beneficial for NAFLD. Coffee consumption represent a good example. Because of its impact on the pro-inflammatory state, the role of coffee consumption has been explored both in NAFLD and MS (Table 2) [60]. Coffee supplementation attenuates the expected onset of an adverse metabolic pattern in animals fed high-fat diets [52, 53]. Similarly, other studies demonstrate that coffee improves fatty liver infiltration in animal models of NAFLD [54]. Potential biological mechanisms underlying the benefits of coffee on NAFLD include: anti-oxidation, inhibiting hepatic stellate cells and the expression of connective tissue growth factor, and lowering serum levels of aminotransferases [51]. It has also been hypothesized that the regulative effect of coffee consumption on the gut microbiota may potentially contribute to reducing the risk of NAFLD. The bioactive coffee components seem to be able to modulate gut microbiota in the sense of conferring a beneficial effect to it (increasing Bifidobacterium spp. Population [55], increasing the ratio between Firmicutes and Bacteroidetes [56]). This finding well introduces the fundamental role of gut microbiota in modifying the metabolic profiles of each individual. On the other hand, tobacco exposure may facilitate the progression of NAFLD.

It is now well-recognized in humans that changes in microbiota composition, termed dysbiosis, are strongly associated with the development of both obesity and NAFLD [57, 58]. Modifications in gut flora metabolism can be strongly influenced by diet. The ingestion of foods that are higher in refined sugar and fats can cause dysbiosis and an overwhelming presence of gut-derived microbial products, therefore activating the innate immunity and the inflammation cascade when IP is impaired. 
Obesity is associated with specific changes in gut microbiota composition. The mechanisms underlying the association of specific gut microbiota and metabolic disease include increasing energy harvest from the diet, changes in host gene expression, energy expenditure and storage, and alterations in gut permeability leading to metabolic endotoxemia, inflammation and insulin resistance. In some studies, the modifications of gut microbiota induced by antibiotics, prebiotics and probiotics lead to improved inflammatory activity in parallel with the amelioration of insulin sensitivity and decreased adiposity [59].

In mice models of genetic dyslipidemia (Apo-E deficient mice), destrane sulfhate sodium (DSS)-induced intestinal inflammation and consequent increased intestinal permeability (IP) are able to trigger the transition of steatosis to NASH, and how these disorders are efficiently prevented by a therapeutic intervention with a mixture of probiotics [60]. Similar results are also obtained in animal models of high-fat diet-induced liver disease that is attenuated by probiotic treatment [61]. Performing interventions on intestinal microbiota modulates the expression of nuclear receptors, correcting insulin resistance in the liver and the adipose tissues.

An increasing number of human studies have supported a link between certain gut microbiota signatures and obesity-related disorders [62-64]. However, it is still not fully understood how microbiota interact with the human body, and, consequently, how they affect metabolic homeostasis. One of the most important crosstalk between gut microbiota and humans is recognized as the above mentioned 'endotoxaemia' within NAFLD, characterized by elevated circulating lipopolysaccharide (LPS). In a recent study performed on NAFLD children, our research group shows that LPS blood level is increased in these patients, and that it is significantly higher in those with a more severe stage of liver disease [65]. Moreover, intravenous infusion of LPS in an acute human experimental study induces systemic insulin resistance and elevation of inflammatory markers in adipose tissue [66]. Lipopolysaccharide binding protein (LBP), mainly synthesized in the liver, is able to specifically bind to and monomerise exogenous LPS, enabling the endotoxin to be recognized by Toll-like receptor 4 (TLR4) and cluster of differentiation 14 (CD14), which are responsible for consequent innate immunity [67]. Circulating LBP levels have been used as a variable to assess endotoxaemia status and its immune responses [68]. In a case-control study by Liu et al., increased plasma LBP is associated with a higher prevalence of MS and type 2 diabetes, but these associations are considerably attenuated when controlling for inflammatory markers [69]. This suggests that gut microbiota might lead to human metabolic abnormalities by triggering chronic inflammation through LPS invasion [70]. On the other hand, the components of MS, such as hypertriacylglycerolaemia, hyperglycaemia and hyperinsulinaemia, are hypothesized to contribute to endotoxaemia through altering jejunal motility and gastrointestinal transit time, conditions that may favor bacterial overgrowth, and leak endotoxins into the intestinal mucosa [71]. This might also explain the increased prevalence of SIBO in NAFLD patients, as reported by our group [25]. Other studies also find that obese individuals have significantly higher LBP levels compared with their normal-weight counterparts [72]. Moreover, a recent study from Spain reports a significant correlation between gene expressions of LBP and gene expressions related to inflammation and insulin resistance in adipose tissue [73]. Hence, adiposity may play a role in the putative endotoxaemia-metabolic axis. A recent Chinese study has investigated the association between plasma LBP and the 6-year incidence of MS, and the potential modification effects of obesity status on the LBP-MS association in adults. The authors conclude that elevated plasma LBP is positively associated with 6-year MS incidence, especially among normal-weight individuals [74]. This finding supports the hypothesis that an increased IP and a mild degree subsequent endotoxemia are involved both in MS and fatty liver disease pathogenesis, and might link them together.

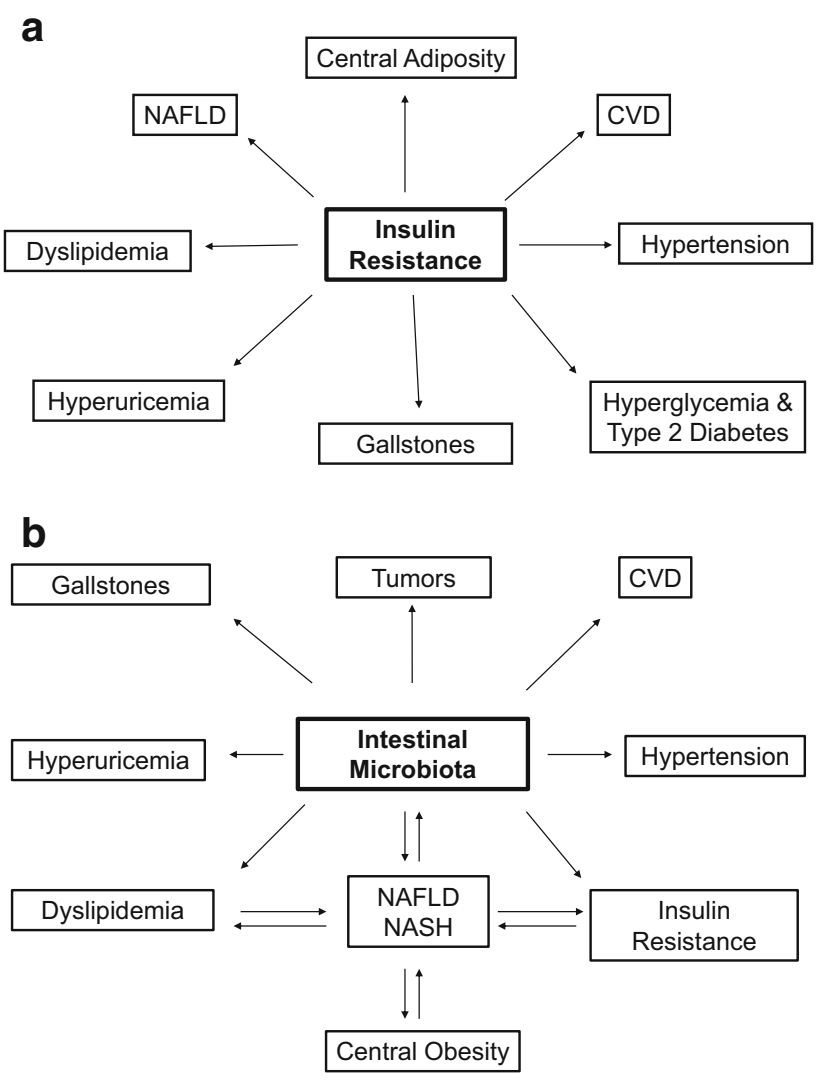

Fig. 1 Possible role of intestinal microbiota in the onset of MS and its clinical manifestations 


\section{Summary and conclusions}

Various basic and clinical studies have reported that NAFLD appears to be linked with MS and its components, and that the presence of a fatty liver may accelerate the onset of the main cardiovascular and systemic co-morbidities. Insulin resistance, proinflammatory cytokines, dysbiosis and altered intestinal permeability and motility may outline the so called "metabolic-liver-disease," where the "borders" defining one disease or another become poorly identifiable (Fig. 1) [75]. NAFLD appears central in this pathological entity, and may be the warning thunder before the metabolic rain starts.

\section{Compliance with ethical standards}

Conflict of interest The authors declare that they have no conflict of interest.

Statements of human and animal rights This article does not contain any studies with human participants or animals performed by any of the authors.

\section{Informed consent None.}

Financial disclosure None.

\section{References}

1. Marchesini G, Brizi M, Bianchi G et al (2001) Nonalcoholic fatty liver disease: a feature of the metabolic syndrome. Diabetes 50:1844-1850

2. Miele L, Bosetti C, Turati F et al (2015) Diabetes and insulin therapy, but not metformin. Are Related to Hepatocellular Cancer Risk, Gastroenterol Res Pract $\mathbf{5 7 0 3 5 6}$

3. Fracanzani AL, Valenti L, Bugianesi E et al (2011) Risk of nonalcoholic steatohepatitis and fibrosis in patients with nonalcoholic fatty liver disease and low visceral adiposity. J Hepatol 54(6):1244-1249

4. Hashemipour S, Esmailzadehha N, Hamid H et al (2015) Association of metabolic syndrome components with insulin resistance in normal weight population: the Qazvin Metabolic Diseases study. J Endocrinol Invest 10:1111-1115

5. Miele L, Targher G (2015) Understanding the association between developing a fatty liver and subsequent cardio-metabolic complications Expert Rev. Gastroenterol Hepatol 29:1-3

6. Chalasani N, Younossi Z, Lavine JE et al (2012) American Association for the Study of Liver Diseases; American College of Gastroenterology; American Gastroenterological Association. The diagnosis and management of non-alcoholic fatty liver disease: practice guideline by the American Association for the Study of Liver Diseases, American College of Gastroenterology, and the American Gastroenterological Association. Am J Gastroenterol 107:811-826

7. Anstee QM, Targher G, Day CP (2013) Progression of NAFLD to diabetes mellitus, cardiovascular disease or cirrhosis. Nat Rev Gastroenterol Hepatol 10:330-344

8. Scholze J, Alegria E, Ferri C et al (2010) Epidemiological and economic burden of metabolic syndrome and its consequences in patients with hypertension in Germany, Spain and Italy; a prevalence-based model. BMC Public Health 10:529
9. Yilmaz Y (2012) Is nonalcoholic fatty liver disease the hepatic expression of the metabolic syndrome? World J Hepatol 4(12):332-334

10. Vanni E, Bugianesi E, Kotronen A et al (2010) From the metabolic syndrome to NAFLD or vice versa? Dig Liver Dis 42(5):320-330

11. Yki-Järvinen H (2014) Non-alcoholic fatty liver disease as a cause and a consequence of metabolic syndrome. Lancet Diabetes Endocrinol 2(11):901-910

12. Machado MV, Cortez-Pinto H (2014) Management of fatty liver disease with the metabolic syndrome. Expert Rev Gastroenterol Hepatol 8(5):487-500

13. Lonardo A, Ballestri S, Marchesini G et al (2015) Nonalcoholic fatty liver disease: a precursor of the metabolic syndrome. Dig Liver Dis 47(3):181-190

14. Samuel VT, Shulman GI (2012) Mechanisms for insulin resistance: common threads and missing links. Cell 148(5):852-871

15. Potenza MV, Mechanick JI (2009) The metabolic syndrome: definition, global impact, and pathophysiology. Nutr Clin Pract 24(5):560-577

16. Visser ME, Lammers NM, Nederveen AJ et al (2011) Hepatic steatosis does not cause insulin resistance in people with familial hypobetalipoproteinaemia. Diabetologia 54(8):2113-2121

17. Mancina RM, Matikainen N, Maglio C et al (2015) Paradoxical dissociation between hepatic fat content and de novo lipogenesis due to PNPLA3 sequence variant. J Clin Endocrinol Metab 100(5):E821-E825

18. Al-Serri A, Anstee QM, Valenti L et al (2012) The SOD2 C47T polymorphism influences NAFLD fibrosis severity: evidence from case-control and intra-familial allele association studies. J Hepatol 56:448-454

19. Miele L, Beale G, Patman G et al (2008) The Kruppel-like factor 6 genotype is associated with fibrosis in nonalcoholic fatty liver disease. Gastroenterology 135(1):282-291

20. Day CP (2010) Genetic and environmental susceptibility to nonalcoholic fatty liver disease. Dig Dis 28:255-260

21. Tilg H, Moschen AR (2010) Evolution of inflammation in nonalcoholic fatty liver disease: the multiple parallel hits hypothesis. Hepatology 52:1836-1846

22. Miele L, Marrone G, Lauritano C et al (2013) Gut-liver axis and microbiota in nafld: insight pathophysiology for novel therapeutic target. Curr Pharm Des 19:5314-5324

23. Frasinariu OE, Ceccarelli S, Alisi A et al (2013) Gut-liver axis and fibrosis in nonalcoholic fatty liver disease: an input for novel therapies. Dig Liver Dis 45:543-551

24. Minemura M, Shimizu S (2015) Gut microbiota and liver diseases. World J Gastroenterol 21(6):1691-1702

25. Miele L, Valenza V, La Torre G et al (2009) Increased intestinal permeability and tight junction alterations in nonalcoholic fatty liver disease. Hepatology 49:1877-1887

26. Yang L, Seki E (2012) Toll-like receptors in liver fibrosis: cellular crosstalk and mechanisms. Front Physiol 22(3):138

27. Lin RS, Lee FY, Lee SD et al (1995) Endotoxemia in patients with chronic liver diseases: relationship to severity of liver diseases, presence of esophageal varices, and hyperdynamic circulation. J Hepatol 22:165-172

28. Chan CC, Hwang SJ, Lee FY et al (1997) Prognostic value of plasma endotoxin levels in patients with cirrhosis. Scand J Gastroenterol 32:942-946

29. Wiest R, Garcia-Tsao G (2005) Bacterial translocation (BT) in cirrhosis. Hepatology 41:422-433

30. Younossi ZM, Reyes MJ, Mishra A et al (2014) Systematic review with meta-analysis: non-alcoholic steatohepatitis - a case for personalised treatment based on pathogenic targets. Aliment Pharmacol Ther 39(1):3-14 
31. Alberti KG, Zimmet P, Shaw J (2005) IDF Epidemiology Task Force Consensus Group. The metabolic syndrome: a new worldwide definition. Lancet 366:1059-1062

32. McGarry JD (2002) Banting lecture 2001: dysregulation of fatty acid metabolism in the etiology of type 2 diabetes. Diabetes $51: 7-18$

33. Zhang T, Zhang Y, Zhang C et al (2014) Prediction of metabolic syndrome by non-alcoholic fatty liver disease in northern urban Han Chinese population: a prospective cohort study. PLoS One 9(5):e96651

34. Bedogni G, Gastaldelli A, Manco M et al (2012) Relationship between fatty liver and glucose metabolism: a cross-sectional study in 571 obese children. Nutr Metab Cardiovasc Dis 22(2):120-126

35. Gill HK, Wu GY (2006) Non-alcoholic fatty liver disease and the metabolic syndrome: effects of weight loss and a review of popular diets. Are low carbohydrate diets the answer? World J Gastroenterol 12(3):345-353

36. Wanless IR, Lentz JS (1990) Fatty liver hepatitis (steatohepatitis) and obesity: an autopsy study with analysis of risk factors. Hepatology 12:1106-1110

37. Klain J, Fraser D, Goldstein J et al (1989) Liver histology abnormalities in the morbidly obese. Hepatology 10:873-876

38. Willner IR, Waters B, Patil SR et al (2001) Ninety patients with nonalcoholic steatohepatitis: insulin resistance, familial tendency, and severity of disease. Am J Gastroenterol 96:2957-2961

39. Bellentani S, Saccoccio G, Masutti F et al (2000) Prevalence of and risk factors for hepatic steatosis in Northern Italy. Ann Intern Med 132:112-117

40. Marchesini G, Brizi M, Morselli-Labate AM et al (1999) Association of nonalcoholic fatty liver disease with insulin resistance. Am J Med 107:450-455

41. Marchesini G, Bugianesi E, Forlani G et al (2003) Nonalcoholic fatty liver, steatohepatitis, and the metabolic syndrome. Hepatology 37:917-923

42. Kassi E, Pervanidou P, Kaltsas G et al (2011) Metabolic syndrome:definitions and controversies. BMC Med 9:48

43. Cambuli VM, Musiu MC, Incani M et al (2008) Assessment of adiponectin and leptin as biomarkers of positive metabolic outcomes after lifestyle intervention in overweight and obese children. J Clin Endocrinol Metab 93:3051-3057

44. Biasucci LM, Graziani F, Rizzello V et al (2010) Paradoxical preservation of vascular function in severe obesity. Am J Med 123(8):727-734

45. Andrade-Oliveira V, Câmara NO, Moraes-Vieira PM (2015) Adipokines as drug targets in diabetes and underlying disturbances. J Diabetes Re 2015:681612

46. Steppan CM, Bailey ST, Bhat S et al (2001) The hormone resistin links obesity to diabetes. Naturev 409:307-312

47. Shai I, Schulze MB, Manson JE et al (2005) A prospective study of soluble tumor necrosis factor-alpha receptor II (sTNF-RII) and risk of coronary heart disease among women with type 2 diabetes. Diabetes Care 28:1376-1382

48. Manco M, Marcellini M, Giannone G et al (2007) Correlation of serum TNF-alpha levels and histologic liver injury scores in pediatric nonalcoholic fatty liver disease. Am J Clin Pathol 127(6):954-960

49. Wieckowska A, Papouchado BG, Li Z et al (2008) Increased hepatic and circulating interleukin-6 levels in human nonalcoholic steatohepatitis. Am J Gastroenterol 103(6):1372-1379

50. Yilmaz Y (2012) Review article: is non-alcoholic fatty liver disease a spectrum, or are steatosis and non-alcoholic steatohepatitis distinct conditions? Aliment Pharmacol Ther 36(9):815-823

51. Yesil A, Yilmaz Y (2013) Review article: coffee consumption, the metabolic syndrome and non alcoholic fatty liver disease. Aliment Pharmacol Ther 38(9):1038-1044
52. Fukushima Y, Kasuga M, Nakao K et al (2009) Effects of coffee on inflammatory cytokine gene expression in mice fed high-fat diets. J Agric Food Chem 57(23):11100-11105

53. Abrahão SA, Pereira RG, de Sousa RV et al (2013) Influence of coffee brew in metabolic syndrome and type 2 diabetes. Plant Foods Hum Nutr 68(2):184-189

54. Vitaglione P, Morisco F, Mazzone G et al (2010) Coffee reduces liver damage in a rat model of steatohepatitis: the underlying mechanisms and the role of polyphenols and melanoidins. Hepatology 52(5):1652-1661

55. Jaquet M, Rochat I, Moulin J et al (2009) Impact of coffee consumption on the gut microbiota: a human volunteer study. Int J Food Microbiol 130:117-121

56. Cowan TE, Palmn€as MS, Yang J et al (2014) Chronic coffee consumption in the diet-induced obese rat: impact on gut microbiota and serum metabolomics. J Nutr Biochem 25:489-495

57. Zhu L, Baker SS, Gill C et al (2013) Characterization of gut microbiomes in nonalcoholic steatohepatitis (NASH) patients: a connection between endogenous alcohol and NASH. Hepatology 57:601-609

58. Spencer MD, Hamp TJ, Reid RW et al (2011) Association between composition of the human gastrointestinal microbiome and development of fatty liver with choline deficiency. Gastroenterology 40:976-986

59. Zhao L (2013) The gut microbiota and obesity: from correlation to causality. Nat Rev Microbiol 11:639-647

60. Mencarelli A, Cipriani S, Renga B et al (2012) VSL\#3 resets insulin signaling and protects against NASH and atherosclerosis in a model of genetic dyslipidemia and intestinal inflammation. PLoS One 7(9):e45425

61. Ritze Y, Bárdos G, Claus A et al (2014) Lactobacillus rhamnosus GG protects against non-alcoholic fatty liver disease in mice. PLoS One 9(1):e80169

62. Ritze Y, Bárdos G, Claus A et al (2014) Lactobacillus rhamnosus GG protects against non-alcoholic fatty liver disease in mice. PLoS ONE 9(1):e80169

63. Vijay-Kumar M, Aitken JD, Carvalho FA et al (2010) Metabolic syndrome and altered gut microbiota in mice lacking Toll-like receptor 5. Science 328:228-231

64. Qin J, Li Y, Cai Z et al (2012) A metagenome-wide association study of gut microbiota in type 2 diabetes. Nature 490:55-60

65. Giorgio V, Miele L, Principessa L et al (2014) Intestinal permeability is increased in children with non-alcoholic fatty liver disease, and correlates with liver disease severity. Dig Liver Dis 46(6):556-560

66. Mehta NN, McGillicuddy FC, Anderson PD et al (2010) Experimental endotoxemia induces adipose inflammation and insulin resistance in humans. Diabetes 59:172-181

67. Schumann RR (2011) Old and new findings on lipopolysaccharide binding protein: a soluble pattern-recognition molecule. Biochem Soc Trans 39:989-993

68. Ruiz AG, Casafont F, Crespo J et al (2007) Lipopolysaccharidebinding protein plasma levels and liver TNF-alpha gene expression in obese patients: evidence for the potential role of endotoxin in the pathogenesis of non-alcoholic steatohepatitis. Obes Surg 17:1374-1380

69. Sun L, Yu Z, Ye X et al (2010) A marker of endotoxemia is associated with obesity and related metabolic disorders in apparently healthy Chinese. Diabetes Care 33:1925-1932

70. Kemp DM (2013) Does chronic low-grade endotoxemia define susceptibility of obese humans to insulin resistance via dietary effects on gut microbiota? Adipocyte 2:188-190

71. Teixeira TF, Souza NC, Chiarello PG et al (2012) Intestinal permeability parameters in obese patients are correlated with metabolic syndrome risk factors. Clin Nutr 31:735-740 
72. Gonzalez-Quintela A, Alonso M, Campos J et al (2013) Determinants of serum concentrations of lipopolysaccharide-binding protein (LBP) in the adult population: the role of obesity. PLoS ONE 8:e54600

73. Moreno-Navarrete JM, Escote X, Ortega F et al (2013) A role for adipocyte-derived lipopolysaccharide-binding protein in inflammation- and obesity-associated adipose tissue dysfunction. Diabetologia $56: 2524-2537$
74. Liu X, Lu L, Yao P et al (2014) Lipopolysaccharide binding protein, obesity status and incidence of metabolic syndrome: a prospective study among middle-aged and older Chinese. Diabetologia 57(9):1834-1841

75. Brunt EM (2009) What's in a NAme? Hepatology 50(3):663-667 